\title{
Behavior Rating Inventory of Executive Function, Preschool Version
}

National Cancer Institute

\section{Source}

National Cancer Institute. Behavior Rating Inventory of Executive Function, Preschool

Version. NCI Thesaurus. Code C121458.

A standardized rating scale designed to specifically measure executive function in children aged 2 to 5 years. Parents, teachers, or other caregivers rate a child's executive functions within the context of the child's home or preschool environments. 